\title{
A bibliometria e as novas atribuições profissionais em bibliotecas universitárias
}

\author{
Bibliometrics and new professional assignments in university libraries
}

\begin{abstract}
Samile Andrea de Souza Vanz
Doutora em Comunicação e Informação pela Universidade Federal do Rio Grande do Sul - UFRGS. Professora associada do Departamento de Ciências da Informação e do Programa de Pós-graduação em Comunicação e Informação da Universidade Federal do Rio Grande do Sul - UFRGS.

E-mail: $\underline{\text { samilevanz@ terra.com.br }}$
\end{abstract}

Dirce Maria Santin

Doutoranda em Comunicação e Informação pela Universidade Federal do Rio Grande do Sul - UFRGS. Bibliotecária do Instituto de Ciências Básicas da Saúde da Universidade Federal do Rio Grande do Sul -

UFRGS.

E-mail: dirce.santin@ufrgs.br

Caterina Marta Groposo Pavão

Doutora em Comunicação e Informação pela Universidade Federal do Rio Grande do Sul - UFRGS. Bibliotecária do Centro de Processamento de Dados da Universidade Federal do Rio Grande do Sul - UFRGS.

E-mail: caterina@cpd.ufrgs.br

\section{Resumo}

$\mathrm{O}$ avanço tecnológico e o contexto acadêmico em rápida transformação têm gerado novas demandas informacionais e promovido a reconfiguração dos serviços em bibliotecas universitárias do mundo todo. As funções tradicionais cedem espaço ao surgimento de novas atribuições, adaptadas à agilidade tecnológica, ao ecossistema dinâmico de informação e às novas demandas dos usuários no contexto acadêmico. Este artigo discute os novos papéis das bibliotecas universitárias e o uso da bibliometria como estratégia para o desenvolvimento das bibliotecas acadêmicas. Com base na literatura e em exemplos de unidades de informação que oferecem serviços de bibliometria, atenta-se para as atribuições emergentes nas bibliotecas universitárias e para as novas possibilidades de atuação profissional. Alguns serviços de bibliometria voltados à avaliação institucional, ao apoio ao pesquisador e à formação de competências são apresentados ao final, incentivando seu oferecimento em bibliotecas universitárias brasileiras. Conclui-se que as atividades relacionadas à bibliometria representam uma importante oportunidade de trabalho para o bibliotecário e um recurso estratégico para o desenvolvimento das bibliotecas universitárias e suas instituições, podendo ter reflexos significativos sobre o planejamento e avaliação institucional.

Palavras-chave: Bibliometria. Bibliotecas universitárias. Serviços de informação.

\begin{abstract}
Technological advancement and the rapidly changing academic context have generated new informational demands and promoted the reconfiguration of services in university libraries around the world. Traditional functions give way to the emergence of new assignments, adapted to the technological agility, the dynamic information ecosystem and the new demands of users in the academic context. This article discusses the new roles of university libraries and the use of bibliometrics as a strategy for the development of academic libraries. Based on the literature and examples of information units that offer bibliometrics services, attention is paid to the emerging assignments in university libraries and to new possibilities for professional action. Some bibliometrics services focused on institutional evaluation, support to the researcher and competencies formation are presented at the end, encouraging their offer in Brazilian university libraries. It is concluded that activities related to bibliometrics represent an important opportunity for the librarian and a strategic resource for the development of university libraries and their institutions, and may have significant repercussions on institutional planning and evaluation.
\end{abstract}

Keywords: Bibliometrics. University libraries. Information services. 


\section{Introdução}

As últimas décadas registraram alterações significativas nas bibliotecas universitárias e nas competências requeridas do bibliotecário acadêmico, provocadas, em parte, pela explosão informacional e pelo avanço tecnológico, pelo surgimento da Internet e pela facilidade de acesso à informação no contexto digital, entre outros fatores. Esse cenário exige novas competências e novos serviços para as bibliotecas universitárias. A importância da biblioteca passa a ser avaliada não apenas por sua capacidade de gerir coleções (impressas e digitais) e de garantir seu acesso à comunidade acadêmica, mas também por sua contribuição para a otimização dos resultados das instituições acadêmicas que as acolhem. Os serviços oferecidos pelas bibliotecas podem ir além das atividades de gestão e recuperação da informação, cuja importância permanece relevante na atualidade, ampliando suas competências para o tratamento e fornecimento de informações com valor agregado em relação aos insumos e resultados das pesquisas realizadas nas instituições (BALL; TUNGER, 2006).

Tradicionalmente o bibliotecário esteve focado na aquisição e organização das coleções das bibliotecas, bem como na pesquisa e recuperação de informações para os usuários. No entanto, a partir do acesso online às fontes de informação, as atividades de busca e recuperação da informação são comumente feitas pelos próprios usuários (ASTRÖM; HANSSON, 2012). Tal mudança leva os bibliotecários a perceberem a necessidade de redefinir seus papéis profissionais. Bibliotecas e bibliotecários devem engajar-se com a comunidade acadêmica para viabilizar o entendimento das mudanças que vêm acontecendo na universidade, possibilitando que as bibliotecas entendam as necessidades informacionais de seus usuários e ofereçam recursos e serviços adequados ao momento (CREASER; SPEZI, 2014).

Mudanças substanciais também são evidenciadas nas formas como os resultados das pesquisas acadêmicas são avaliados, gerando implicações na distribuição do financiamento de projetos por órgãos governamentais e agências de fomento e nas práticas de produção do conhecimento científico. Os métodos bibliométricos vêm sendo bastante utilizados para levantamento de indicadores quantitativos da produtividade e visibilidade da produção acadêmica. A implementação institucionalizada de práticas bibliométricas em bibliotecas universitárias é motivada pela necessidade de prover mais serviços relacionados à comunicação científica, incrementando a visibilidade, o prestígio e a competência do profissional no gerenciamento de dados estratégicos para a instituição e seus pesquisadores. A análise 
bibliométrica pode ser uma das atividades assumidas pelos bibliotecários dentro do contexto atual das universidades.

A bibliometria teve origem em 1743, em análises de citações realizadas no âmbito jurídico. O primeiro estudo bibliométrico, datado de 1790, abordava uma pesquisa sobre produção e comércio de livros, já o primeiro levantamento estatístico sobre jornais foi publicado em 1828. A análise de desenvolvimento dos países baseada em métodos matemáticos foi inaugurada em 1873, mas foi somente no início do século XX que os estudos bibliométricos se multiplicaram. E, em 1923, o termo estatística bibliográfica foi empregado pela primeira vez. O termo bibliometria foi cunhado pelo belga Paul Otlet em 1934, na obra "Traité de Documentation: le livre sur le livre". Otlet definiu a bibliometria como parte da bibliologia que trata da medida ou quantidade aplicada aos livros (VARGAS, 2014).

Desde então, a bibliometria se expandiu em várias áreas, especialmente na Ciência da Informação. Sua consolidação fortaleceu-se a partir de 1979, com a publicação do periódico internacional Scientometrics. Atualmente, o evento bianual International Conference on Scientometrics \& Informetrics, da International Society of Scientometrics and Informetrics (ISSI), reúne os principais pesquisadores e interessados na temática. $\mathrm{O}$ evento correspondente no Brasil, denominado Encontro Brasileiro de Bibliometria e Cientometria (EBBC), acontece também a cada dois anos desde 2008.

Apesar de já reunir uma ampla comunidade de interessados aqui no Brasil, a bibliometria ainda não figura entre o rol de conteúdos obrigatórios na maior parte das instituições que ofertam o curso de graduação em Biblioteconomia, e tampouco figura como oferta sistemática de serviços nas diversas bibliotecas universitárias. Entretanto, algumas iniciativas começam a aparecer, a exemplo do Programa de Bibliometria e Indicadores Científicos do Sistema de Bibliotecas da Universidade de São Paulo (SIBi-USP), que desenvolve estudos, mapeamentos e análises bibliométricas sobre a produção científica institucional. O Programa congrega o Grupo de Estudos Bibliométricos do SIBiUSP, gera indicadores para a instituição e disponibiliza ferramentas de análise bibliométrica para a comunidade da USP.

Em outros países, o estabelecimento da bibliometria como um serviço nas bibliotecas universitárias alterou a imagem e identidade da biblioteca e dos profissionais bibliotecários e sua relação com as instituições. O cargo "bibliometrista" (bibliometrician) é realidade em muitas bibliotecas europeias em países como Suécia, Alemanha e Holanda (BALL; TUNGER, 
2006; ASTRÖM; HANSSON, 2012). Nesses países, o foco está no desenvolvimento de conhecimentos e serviços relacionados à comunicação científica, ao invés da atuação simples na pesquisa e recuperação de informação, e na oferta de análises bibliométricas para avaliação de performance e distribuição de recursos em nível institucional, de institutos e faculdades (ASTRÖM; HANSSON, 2012).

Considerando as mudanças em curso e a necessidade de redefinição dos papéis das bibliotecas universitárias e de ampliação de suas competências, este artigo discute o uso da bibliometria como recurso estratégico para o desenvolvimento das bibliotecas no contexto acadêmico. Com base na literatura sobre o assunto e em exemplos de unidades de informação que oferecem serviços de bibliometria em diversos países, atenta-se para as atribuições emergentes nas bibliotecas universitárias e para as novas possibilidades de atuação do profissional bibliotecário. Alguns serviços de bibliometria voltados à avaliação institucional, ao apoio ao pesquisador e ao desenvolvimento de competências são propostos ao final, incentivando o oferecimento de novos serviços nas bibliotecas universitárias brasileiras.

\section{Novos papéis da biblioteca universitária}

As funções tradicionais da biblioteca universitária foram cedendo espaço ao surgimento de novas atribuições, adaptadas à agilidade tecnológica, ao ecossistema dinâmico de informação e às novas demandas dos usuários no contexto acadêmico. O bibliotecário assumiu o papel de agente ativo no processo de ensino/aprendizagem de estudantes, professores e grupos de pesquisa, o que, sem dúvida, agrega valor ao profissional. Nesta linha, os serviços de apoio oferecidos aos pesquisadores constituem uma das principais tendências, junto com os repositórios, os sistemas de descoberta e o desenvolvimento de competências informacionais para o uso de ferramentas e recursos eletrônicos de informação (ASSOCIATION OF COLLEGE \& RESEARCH LIBRARIES, 2015; IRRIBAREN MAESTRO et al., 2015).

Os serviços de apoio à pesquisa englobam tarefas que vão desde o planejamento da publicação de artigos até a gestão da visibilidade e do impacto da instituição e dos grupos de pesquisa. Irribaren Maestro e colaboradoras (2015) apresentam algumas vantagens da realização de tarefas de apoio à pesquisa, como a valorização da biblioteca entre a comunidade universitária, a ampliação da colaboração com outros setores da universidade, a criação de uma nova frente de trabalho e a melhora da gestão e disseminação das coleções devido ao 
conhecimento das fontes habituais de publicação e uso de informação. No que diz respeito às vantagens para os pesquisadores, as autoras pontuam a ampliação do conhecimento sobre fontes de informação e ferramentas de avaliação, a percepção de apoio para gestão do curriculum vitae, a possibilidade de delegar a pesquisa sobre qualidade e impacto de sua produção e o apoio na difusão de sua produção intelectual. Além disso, destacam-se as vantagens para a universidade, como o incremento da visibilidade da produção científica e a consequente melhoria nas disputas em editais de pesquisa, e a maior cobertura de dados para a gestão da pesquisa no âmbito institucional.

As universidades encontram-se atualmente em meio a um contexto de grande competitividade, marcado pela crise e proliferação dos rankings universitários. Por isso, há maior demanda de informação quantitativa sobre os resultados produzidos pelos pesquisadores, grupos e centros de pesquisa (TORRES-SALINAS; CABEZAS-CLARIJO, 2012). A bibliometria vem se consolidando como ferramenta de gestão da pesquisa e um instrumento a mais para subsidiar a tomada de decisões acerca das políticas científicas: é um instrumento útil para identificar os agentes mais capazes em uma comunidade e orientar a correta alocação de recursos e o estabelecimento de prioridades. A bibliometria avaliativa difere da descritiva, pois é realizada em parceria com o indivíduo avaliado, que participa do início ao fim do processo, provendo a informação necessária, ponderando os indicadores a partir de sua expertise na área. No caso da bibliometria avaliativa, a proatividade do indivíduo avaliado é essencial e a precisão dos resultados exige exaustividade tanto na coleta como na análise dos dados (TORRESSALINAS, JIMENEZ-CONTRERAS, 2012).

Para Torres-Salinas e Jiménez-Contreras (2012) uma unidade de bibliometria deve ser capaz de controlar todas as fontes que armazenam registros sobre todas as atividades intelectuais de uma universidade e converter estas fontes em registros que possam gerar conhecimento sobre as universidades. Assim, as competências desta unidade se relacionam ao conhecimento de fontes de informação, criação de bases de dados e processamento e visualização de indicadores. Os autores fundamentam a unidade de bibliometria em três frentes de trabalho: controle das fontes de informação de pesquisa; desenvolvimento de relatórios de análise, prospectivos e de vigilância; e formação, assessoria e consultoria especializada.

O controle das fontes de informação envolve o acompanhamento da evolução das fontes e da disponibilização dos dados, atividades de normalização de nomes e eliminação de registros duplicados para garantir a qualidade da informação, além da atualização periódica dos dados, 
de modo a permitir a consulta a qualquer momento. Os indicadores bibliométricos gerados devem estar disponíveis a partir de um conjunto de consultas pré-definidas, que facilitem a resposta rápida. A partir do momento em que se tem um banco de dados organizado, é possível gerar conhecimento sobre as atividades de Ciência e Tecnologia (C\&T) da universidade. Nesta etapa, os bibliotecários podem atuar no desenvolvimento de relatórios habituais sobre a situação da universidade, relatórios especializados em um aspecto de interesse estratégico e, também, relatórios de divulgação ao público mais amplo e não especialista. Neste âmbito, o controle e divulgação dos editais de apoio e financiamento a pesquisa também podem constituir um serviço das bibliotecas (TORRES-SALINAS; JIMENEZ-CONTRERAS, 2012).

Por fim, a literatura sugere que a expertise dos bibliotecários seja utilizada para a formação e capacitação da comunidade acadêmica, especialmente por meio de treinamentos sobre indicadores e boas práticas de comunicação científica. Ações nesse sentido já vêm sendo desenvolvidas em bibliotecas universitárias brasileiras, especialmente vinculadas ao Serviço de Referência, com demanda crescente. Conduzidas em conjunto com as unidades de bibliometria, as ações podem ter maior valor agregado e vincular mais fortemente as orientações práticas aos sistemas de avaliação. A assessoria individualizada para preenchimento de currículos, redação e apresentação de artigos, preparação de projetos, redação de cartas ao editor e recursos em casos de retorno negativo também são atividades que podem contribuir para o aumento das taxas de êxito no aceite de artigos pelas revistas científicas, e de projetos de pesquisa por agências de fomento e outros organismos de financiamento. O Quadro 1 apresenta uma adaptação das três frentes de trabalho de uma unidade de bibliometria propostas por TorresSalinas e Jimenez-Contreras (2012): 
Quadro 1 - Pilares e funções da unidade de bibliometria em bibliotecas universitárias

\begin{tabular}{|c|c|c|}
\hline $\begin{array}{l}\text { Controle das fontes de } \\
\text { informação }\end{array}$ & $\begin{array}{l}\text { Desenvolvimento de } \\
\text { relatórios de análise e } \\
\text { prospecção }\end{array}$ & $\begin{array}{c}\text { Formação e assessoria } \\
\text { especializada }\end{array}$ \\
\hline $\begin{array}{l}\text { - Identificação e coleta da } \\
\text { produção em C\&T } \\
\text { (artigos, trabalhos em } \\
\text { eventos, patentes, etc.) } \\
\text { - Normalização de nomes } \\
\text { individuais dos } \\
\text { pesquisadores e de } \\
\text { nomes institucionais } \\
\text { - Unificação de registros } \\
\text { duplicados }\end{array}$ & $\begin{array}{l}\text { - Relatórios da pesquisa } \\
\text { institucional } \\
\text { - Relatórios de divulgação } \\
\text { para o público em geral } \\
\text { - Divulgação de editais e } \\
\text { oportunidades }\end{array}$ & $\begin{array}{l}\text { - Assessoria personalizada } \\
\text { na criação e atualização } \\
\text { de currículos } \\
\text { - Assessoria no uso de } \\
\text { identificadores de } \\
\text { autores } \\
\text { - Orientação sobre o uso } \\
\text { de redes sociais } \\
\text { acadêmicas } \\
\text { - Apoio na preparação de } \\
\text { projetos/documentação } \\
\text { para editais }\end{array}$ \\
\hline $\begin{array}{l}\text { Desenvolvimento de } \\
\text { sistemas para criação dos } \\
\text { indicadores }\end{array}$ & $\begin{array}{c}\text { Divulgação de resultados } \\
\text { dentro e fora da } \\
\text { universidade }\end{array}$ & Oferta de cursos \\
\hline $\begin{array}{l}\text { - Pesquisas } \\
\text { programadas/pré- } \\
\text { definidas } \\
\text { - Configuração de alertas } \\
\text { - Exportação dos dados } \\
\text { - Desenvolvimento de } \\
\text { bancos de dados da } \\
\text { produção científica } \\
\text { institucional } \\
\text { - Análise e visualização de } \\
\text { dados }\end{array}$ & $\begin{array}{l}\text { - Assessorias de imprensa } \\
\text { - Sites institucionais } \\
\text { - Revistas de divulgação } \\
\text { - Redes sociais } \\
\text { - Blogs }\end{array}$ & $\begin{array}{l}\text { - Fontes de informação } \\
\text { - Gerenciadores de } \\
\text { referências } \\
\text { - Redação científica } \\
\text { - Indicadores } \\
\text { - Curriculum vitae } \\
\text { - Identificadores } \\
\text { autores de } \\
\text { - Redes } \\
\text { acadêmicas }\end{array}$ \\
\hline
\end{tabular}

Fonte: adaptado de Torres-Salinas e Jimenez-Contreras, 2012.

O uso da bibliometria para a avaliação sistemática da pesquisa, com o objetivo de fundamentar as decisões estratégicas sobre políticas em C\&T, já é comum em vários países, nos quais a bibliometria vem se tornando uma prática institucionalizada. Aström e Hansson (2012) apontam três razões para que isso aconteça dentro das bibliotecas universitárias. Primeiro, pelo fato da bibliometria ser um método usado pelos pesquisadores de Ciência da Informação, então, nada mais natural que trazê-la para a prática profissional do bibliotecário no contexto das bibliotecas universitárias. A segunda razão diz respeito ao mêtie do profissional bibliotecário, ligado à geração, armazenamento e gestão de grandes conjuntos de dados bibliográficos em bancos de dados. A terceira razão mencionada pelos autores refere-se ao fato das bibliotecas já serem as responsáveis pelo desenvolvimento e manutenção de repositórios institucionais, considerados fontes importantes para análise de produção científica no nível institucional. A competência profissional dos bibliotecários para as análises bibliométricas 
também é destacada por Ball e Tunger (2006); MacCol (2010) e Silva, Hayashi e Hayashi (2011).

Em estudo sobre os regimes de avaliação de alguns países e a possível participação das bibliotecas universitárias nesses processos, MacColl (2010) recomenda que as bibliotecas sejam fontes de conhecimento sobre normas, práticas disciplinares e resultados de pesquisa de suas instituições. Que procurem sustentar ambientes em que as disciplinas possam se desenvolver enquanto coexistem com restrições políticas e econômicas, fazendo recomendações de melhores práticas na comunicação científica e chamando a atenção a mudanças nocivas às disciplinas nos processos de avaliação. Para o autor, as bibliotecas universitárias têm papel significativo no gerenciamento dos resultados de pesquisa no nível institucional, atentando também para os padrões nacionais e internacionais.

Além disso, segundo MacColl (2010), as bibliotecas devem garantir o funcionamento eficiente de repositórios de resultados de pesquisa e desempenhar um papel de liderança no desenvolvimento e manutenção de repositórios de dados de pesquisa. Podem assumir um papel central nas pesquisas oferecendo serviços de bibliometria, com dados e indicadores que expressem o desempenho da instituição e de seus pesquisadores. Desta forma podem exercer seu papel não apenas como provedoras de informação, mas como fontes de informação e de dados bibliométricos institucionais. Na mesma linha, podem fornecer evidências de uso da informação, tanto com as métricas da própria biblioteca (dados de circulação das coleções ou uso de recursos eletrônicos), como com as altmetrias, oferecendo dados que possam complementar os indicadores baseados em citações. Por fim, segundo o autor, as bibliotecas precisam reivindicar seu território e serem mais assertivas sobre as contribuições que podem fazer na avaliação de pesquisa, atuando com liderança e atitude ativa na construção de relacionamentos com departamentos, unidades acadêmicas e órgãos centrais das universidades.

A literatura revela que estão em curso diversas iniciativas que buscam ampliar a integração dos bibliotecários com os processos de pesquisa e comunicação científica nas universidades. Além das atividades de recuperação da informação, as bibliotecas têm contribuído para a promoção do acesso aberto à informação científica tanto no que se refere ao apoio às publicações como no desenvolvimento de repositórios institucionais.

O movimento de Acesso Aberto (AA) já se configura como um tema da área e, em muitas bibliotecas, é parte importante das atividades rotineiras, tendo em vista que um grande volume das publicações científicas encontra-se em meio eletrônico e em AA. Segundo Leite 
(2009), um dos principais atores envolvidos nos processos de criação, registro e disseminação do conhecimento científico na instituição, que pode oferecer diagnóstico útil ao reconhecimento de oportunidades e obstáculos ao estabelecimento de um repositório institucional, são as bibliotecas, como unidades organizacionais mais apropriadas para o gerenciamento e funcionamento dos repositórios institucionais.

Por outro lado ressalta-se que as equipes de bibliotecários responsáveis por viabilizar e desenvolver portais de periódicos, bancos de dados e repositórios devem ser capacitadas para este fim e

[...] que além da internalização dos conceitos fundamentais, os profissionais estejam
aptos a compreender o contexto da comunicação científica e sua lógica, atores,
componentes, processos e as forças que a governam, assim como as propriedades da
informação e do conhecimento científico, o papel das tecnologias de informação e o
funcionamento das comunidades científicas e suas diferenças disciplinares na
produção e comunicação do conhecimento. Em seguida, é indispensável que tenham
ciência do significado do movimento de acesso aberto à informação científica, das
razões de sua emergência como modelo alternativo de comunicaçãa e de seus
pressupostos, premissas e impactos no sistema de comunicação científica como um
todo (LEITE, 2009, p. 41).

A responsabilidade para viabilizar e desenvolver portais de periódicos, bancos de dados e repositórios normalmente é das bibliotecas. Tais repositórios podem ser vistos sob dois ângulos: o primeiro, relacionado à promoção do $\mathrm{AA}$; o segundo, como fonte de dados para as análises bibliométricas. Desta forma, além de promover a divulgação das pesquisas e ampliar a visibilidade da informação científica, os repositórios podem ser usados como importantes fontes de dados para a avaliação da produção científica institucional (AYRIS, 2011).

Atualmente há variadas fontes de dados para a avaliação da pesquisa, com destaque para as bases de dados Web of Science, Scopus e Google Acadêmico, além das ferramentas dedicadas especificamente à avaliação, como InCites e SciVal, produzidas a partir da Web of Science e Scopus, respectivamente. As limitações destas ferramentas, especialmente as comerciais, são recorrentes na literatura: falta de normalização de nomes individuais e institucionais; utilização exclusiva das revistas indexadas - deixando de lado um grande volume de documentos publicados em fontes não indexadas; alto custo de assinatura das bases comerciais; preferência pela indexação de documentos em língua inglesa; preferência por determinados temas - de modo que nem todas as áreas têm a mesma cobertura. No caso do InCites e do SciVal, o custo de manutenção é duplo, tendo em vista que as instituições de pesquisa normalmente assinam a Web of Science e a Scopus. Por estes motivos, especialmente pela possibilidade de busca exaustiva da produção intelectual, considera-se que as bases de 
dados institucionais, ou seja, aquelas produzidas pela própria instituição para gestão e preservação da produção intelectual, podem se converter nas fontes de informação mais adequadas para as avaliações bibliométricas institucionais e de seus pesquisadores (DE FILIPPO et al., 2011), especialmente no caso de instituições com orientação regional ou nacional, enfoque de menor cobertura nas bases de dados internacionais.

As bases de dados institucionais podem dar visibilidade à produção científica que vai além dos veículos tradicionais indexados pelas bases comerciais, produção esta que muitas vezes reflete a transferência de conhecimento para a sociedade. A difusão de produtos como softwares, matérias e artigos de divulgação, documentos de trabalho, cartas e objetos educacionais pode ser possível por meio das bases de dados institucionais, que se convertem em ferramentas poderosas para transmitir os resultados produzidos pelas universidades (DE FILIPPO et al., 2011). Além disso, permitem uma avaliação mais ampla do perfil da ciência produzida pela universidade, se básica ou aplicada; da orientação temática da universidade; e a que comunidade, acadêmica ou profissional, se dirigem as publicações; através da análise dos documentos publicados pela universidade. As bases de dados institucionais permitem maior transparência e comparabilidade dos indicadores de diferentes universidades. Dada a importância das bases institucionais para controle e geração de indicadores da produção intelectual da universidade, justifica-se a dedicação das bibliotecas na manutenção e atualização contínua destes produtos.

Como exemplo pode-se citar o Sistema de Automação de Bibliotecas (SABi) da UFRGS, utilizado para o registro da Produção Intelectual (PI) da Universidade. A automação do processo de catalogação no Sistema de Bibliotecas teve início em 1975 e, a partir de 1989, a coleta e registro de PI passaram a realizar-se de forma contínua e sistemática. Os dados bibliométricos obtidos a partir do SABi têm sido utilizados como fonte para orientar ações institucionais, como por exemplo: determinação do Índice Departamental, avaliação institucional, progressão docente, vagas docentes, entre outros (COSTA et al., 2010).

Além dos repositórios, catálogos e bases institucionais, o Brasil dispõe da Plataforma Lattes, mantida pelo Conselho Nacional de Desenvolvimento Científico e Tecnológico (CNPq) e considerada uma das mais completas fontes de dados sobre currículos, pesquisadores, produção científica e instituições no Brasil. O Currículo Lattes, disponível na Plataforma, tem grande potencial para a extração e análise de dados bibliométricos, de modo que pode ser bastante útil para a análise da produção institucional, de grupos de pesquisa ou de pesquisadores 
individuais. A ferramenta ScriptLattes, desenvolvida por pesquisadores brasileiros, pode ser utilizada para baixar os currículos cadastrados no CNPq, extrair informações acadêmicas e profissionais, criar relatórios de produção, gráficos de colaboração e mapas geográficos de investigação, entre outras funcionalidades (MENA-CHALCO; CESAR JUNIOR, 2009). Além disso, importa destacar que o Currículo Lattes é uma ferramenta muito importante no Brasil, de modo que o apoio ao pesquisador no preenchimento pode ser fundamental.

\section{Bibliotecas universitárias e unidades de bibliometria: exemplos internacionais}

Na década de 2000, as bibliotecas universitárias da Europa iniciaram a oferta de serviços de análise bibliométrica para fundamentar avaliação de performance e a distribuição de recursos, em nível institucional, de faculdades e departamentos (ASTRÖM; HANSSON, 2012). Na Suécia, Aströn e Hansson (2012) analisaram as possíveis consequências da implementação de bibliometria como uma prática institucionalizada em bibliotecas universitárias, com base na experiência de nove bibliotecas do país. Os resultados revelam que as principais motivações para os bibliotecários realizarem atividades bibliométricas são o desafio de oferecer serviços mais completos relacionados à comunicação científica e a necessidade de ampliar a visibilidade e o prestígio das bibliotecas universitárias. Novas competências adquiridas pelos profissionais nas últimas décadas e o desejo de modificar a percepção do perfil profissional dos bibliotecários no ambiente acadêmico também são fatores que estimulam o oferecimento desses serviços.

Nessa perspectiva, bibliotecas universitárias europeias passaram a oferecer, nos últimos anos, serviços de análise bibliométrica voltados à avaliação do desempenho da ciência e da distribuição de investimentos para a pesquisa tanto em nível institucional quanto de pesquisadores individuais. Também na Suécia, os esforços para construção de competências institucionais em bibliometria ganharam força a partir de 2007, com a criação de um grupo de trabalho específico sobre questões bibliométricas no âmbito do Forum for Head/University Librarians in the Association of Swedish Higher Education. Entre as atribuições do grupo estão a criação e o oferecimento de cursos sobre métodos e aplicações bibliométricas em nível local e nacional, visando capacitar os profissionais para o oferecimento de novos serviços nas universidades. Como resultados da iniciativa observaram-se a ampliação das competências profissionais dos bibliotecários e dos serviços oferecidos e a criação de setores específicos nas bibliotecas para tratar dessas questões (ASTROM; HANSSON, 2012). 
Outro exemplo concreto de uso da bibliometria para monitoramento da ciência pelas bibliotecas teve origem nos anos 2000 na biblioteca central do Research Centre Jülich, da Alemanha, que reúne oito institutos nas áreas de Biologia, Química, Física, Medicina e Engenharia. A preocupação com a questão provocou mudanças no escopo de atividades da biblioteca e exigiu a aquisição de novos conhecimentos, além da nomeação de pessoal qualificado e capacitação das equipes envolvidas. A biblioteca passou a oferecer diversos tipos de análise bibliométrica relativas aos resultados do Centro e aos padrões de colaboração e citação de seus membros em relação ao contexto nacional e internacional, além de análises comparativas de produtividade e impacto, mapas e rankings da ciência, estudos de reconhecimento de tendências de pesquisa, entre outros. Os resultados da iniciativa revelam que as análises bibliométricas são viáveis, necessárias e podem aumentar o interesse da instituição e seus públicos não só pela biblioteca mas também pelos serviços oferecidos aos seus usuários (BALL; TUNGER, 2006).

Na Espanha, a biblioteca da Universidad de Navarra, em pareceria com a pró-reitoria de pesquisa, oferece o Servicio de Bibliometría, liderado por bibliotecários com formação em políticas científicas (IRRIBAREN MAESTRO et al., 2015). A equipe apoia as atividades de acreditación y sexenios, processo fundamental na Espanha, através do qual as agências de fomento chancelam ao pesquisador sua produção intelectual e atividades de ensino ao longo de um período. Para receber a chancela os interessados preparam uma extensa documentação que inclui dados de sua produção intelectual, como Quartis e Fator de Impacto dos periódicos informações que para muitos pesquisadores não são conhecidas e por isso, o apoio dos bibliotecários torna-se fundamental para agilizar a busca de informação e a organização da documentação.

O assessoramento para apresentação de projetos em editais também é parte das tarefas do Servicio de Bibliometría da Universidad de Navarra (IRRIBAREN MAESTRO et al., 2015). A Universidade mantém uma ferramenta de gestão de dados de pesquisa que reúne a produção intelectual gerada pelos pesquisadores, o que permite análises bibliométricas mais exaustivas. Assim, a análise bibliométrica gerada a partir de um banco de dados institucional soluciona problemas decorrentes da indexação incompleta das bases de dados comerciais, como a Web of Science e Scopus. Como metas, o referido Servicio de Bibliometría planeja a interligação da ferramenta de gestão de dados com os identificadores de autores Open Researcher and Contributor ID (ORCID) e ResearcherID, bem como com a rede social ResearchGate (IRRIBAREN MAESTO et al., 2015). 
$\mathrm{Na}$ Universidad de Granada, também na Espanha, a Unidade de Bibliometría é responsável pela formação da comunidade em aspectos relacionados à comunicação científica, através da oferta de cursos, tais como: "Como comunicar e disseminar seus resultados de pesquisa através da web"; "Como publicar em revistas científicas de impacto"; "Como preparar um projeto de pesquisa para um edital competitivo"; "Buscas em bases de dados científicas: resgate de citações e criação de perfis"; "Como gerenciar um projeto de pesquisa", entre outros (TORRES-SALINAS; JIMENEZ-CONTRERAS, 2012). Além disso, a Unidade produz o catálogo de grupos de pesquisa da Universidade e divulga informes bibliométricos, rankings de pesquisadores, relatórios anuais de pesquisa e outros materiais informativos.

Na mesma linha, a biblioteca da universidade espanhola Universitat Pompeu Fabra implementou algumas atividades para difundir a produção científica institucional: criação de um repositório institucional; criação de um Portal de Produção Científica, que permite a gestão dos currículos dos pesquisadores em vários formatos e idiomas; difusão de recomendações sobre a normalização de nomes e filiação dos autores; difusão de índices de revistas, citações e de pesquisadores com o objetivo de melhorar o perfil individual e outras iniciativas (BLANCO; CASALDÀLIGA, 2012). A biblioteca também é responsável pela oferta de cursos acerca das ferramentas que contabilizam as citações dos pesquisadores, como Índice h; ferramentas de perfil profissional, como ResearcherID e Google-Scholar My Citations; dicas de como melhorar o currículo, como por exemplo, em que revistas publicar para melhorar a visibilidade e pontuar melhor no momento de pleitear financiamento ou bolsas.

Ainda no contexto europeu, uma pesquisa realizada na Suécia demonstrou que 18 das 48 bibliotecas universitárias do país ofereciam atividades bibliométricas organizadas na década 2000 (CARLSSON; HALLGREN, $2008^{1}$ apud ASTRÖM; HANSSON, 2012). Quando questionadas sobre a organização dessas atividades, algumas bibliotecas responderam que dispunham de profissionais em tempo integral para as atividades, enquanto outras as realizavam conforme demanda. Entre os profissionais responsáveis pelas atividades, a pesquisa relata situações bem diversas: alguns com doutorado em Estatística ou áreas com foco quantitativo, e alguns profissionais com mestrado em Ciência da Informação, a maior parte deles sem treinamento formal em bibliometria. Em relação ao público atendido, as bibliotecas

\footnotetext{
${ }^{1}$ CARLSSON, Hakan; HÄLLGREN, Marianne. Inventering av bibliometrisk verksamhet vid svenska larosaten. Report: Arbetsgruppen för Bibliometri: SUHF/Forum för Bibliotekschefer, 2008.
} 
responderam ser basicamente a administração das universidades e faculdades, muito mais do que os pesquisadores individuais.

Creaser e Spezi (2014) advogam pela ideia de que a biblioteca deve aproximar-se da comunidade acadêmica para que seu valor seja percebido. As autoras argumentam que a aproximação é necessária para que pesquisadores e bibliotecários entendam mutuamente suas tarefas, seu modo de trabalho e possam, efetivamente, colaborar. As autoras analisaram bibliotecas dos Estados Unidos, Reino Unido, Noruega e Suécia, e encontraram resultados que mostram que o desenvolvimento de competências informacionais específicas por cursos é a atividade mais valorizada entre os professores e pesquisadores da universidade. O grupo entrevistado pelas autoras também aponta um considerável grau de importância aos serviços orientados ao acesso aberto e à bibliometria, a exemplo do apoio à pesquisa bibliográfica, apoio no arquivamento de publicações em repositórios, apoio para publicar em acesso aberto, além do serviço de análises bibliométricas. Uma das tendências apontadas pelos bibliotecários entrevistados diz respeito à colaboração na redação de projetos de pesquisa e nas atividades de revisão sistemática da literatura. A curadoria de dados de pesquisa também se destaca como um dos serviços de grande utilidade apontados no estudo.

Outro projeto interessante é o MyRI: Measuring your Research Impact, lançado em 2011 por quatro bibliotecas universitárias irlandesas. Atualmente o MyRI é mantido pelas bibliotecas da Dublin City University, Moynooth University e University College Dublin, que produzem materiais eletrônicos para treinamento de bibliotecários (MyRI, 2015). O site inclui apresentações prontas em Power Point, tutoriais, documentos em formato PDF e vídeos que podem ser utilizados para o treinamento de equipes de bibliotecários em temas como Introdução à bibliometria, Fator de Impacto, Índice h, ORCID, entre outros. Os materiais podem ser utilizados tanto com vistas à realização de análises bibliométricas pelos profissionais bibliotecários como para a replicação dos conteúdos em atividades formativas junto às comunidades acadêmicas de suas instituições.

A partir dos exemplos apresentados é possível perceber a importância crescente da bibliometria no meio acadêmico e as novas possibilidades das bibliotecas nesse contexto. As novas atividades desenvolvidas pelas bibliotecas podem se configurar numa importante estratégia para ampliar seu papel junto à comunidade acadêmica, de modo que o monitoramento do desempenho das pesquisas institucionais ande lado a lado com os serviços tradicionais. As bibliotecas também podem alcançar um novo patamar com a oferta de serviços bibliométricos. 
Desta forma, a função das bibliotecas como provedoras de informação pode ser complementada pelo fornecimento de informações processadas e com valor agregado, ampliando o alcance e o impacto de suas atividades na comunidade acadêmica (BALL; TUNGER, 2006; ASTRÖM; HANSSON, 2012).

\section{Serviços de bibliometria em bibliotecas universitárias}

Há algumas décadas as bibliotecas universitárias do mundo todo passaram a repensar os serviços que oferecem, inclinando-se para uma visão cada vez mais centrada no usuário. Este é representado, muitas vezes, pelos pesquisadores vinculados às instituições. Instrumentos como currículos, índices, identificadores de autores e, mais recentemente, uma série de ferramentas de redes sociais passaram a ser utilizadas pelos pesquisadores para divulgar mais amplamente seus trabalhos, além de compreender e avaliar o uso das publicações no âmbito de suas disciplinas. As novas configurações exigem das bibliotecas novas estratégias de atuação, repensando suas atribuições e os produtos e serviços de informação oferecidos no contexto acadêmico.

O ambiente acadêmico em rápida transformação reconfigura as bibliotecas universitárias e lhes confere novas atribuições. As bibliotecas precisam compreender essas mudanças e como elas afetam as necessidades e o comportamento dos pesquisadores nas diferentes áreas do conhecimento. Nesta perspectiva, as bibliotecas universitárias têm a oportunidade de participar mais ativamente dos processos de pesquisa e avaliação dos resultados da ciência, tanto pela oferta de orientações, capacitações e serviços de bibliometria, como pelo apoio à comunicação científica. Esses serviços podem ter diferentes níveis de importância entre áreas ou espaços geográficos, mas tendem a ser relevantes nos diversos ambientes e culturas. As bibliotecas precisam conhecer esses ambientes e as práticas e valores de cada comunidade, de modo a compreender melhor as demandas existentes e suas próprias atribuições no contexto institucional (MACCOLL, 2010).

Pérez (2010) chama a atenção para as mudanças em curso e para as novas competências de bibliotecas e bibliotecários. Segundo a autora, em um mundo centrado na informação digital, a biblioteca universitária ou especializada em ciência e tecnologia precisa avançar para um cenário de interação pessoal, presencial e virtual com a criação de serviços que facilitem aos pesquisadores lidar com a grande quantidade de informação disponível. Para ela, as necessidades dos usuários requerem do bibliotecário novas habilidades e competências, cada 
vez mais diversas, e entre elas está a de realizar análises bibliométricas. Assim, também para as bibliotecas, cabe o desafio de oferecer serviços adequados às novas necessidades dos usuários, sejam eles estudantes, pesquisadores ou profissionais.

Com base na revisão de literatura e nas experiências internacionais apresentadas, este trabalho sugere alguns serviços que podem ser oferecidos pelas bibliotecas universitárias para apoiar os processos de produção e avaliação da pesquisa. A maioria desses serviços aplica-se ao nível institucional, de pesquisadores e grupos de pesquisa, mas os benefícios da avaliação institucional e da formação dos pesquisadores também podem ter implicações sobre os sistemas nacionais de ciência e tecnologia. Diversas dessas iniciativas estão consolidadas em instituições do exterior e têm aparecido em iniciativas de bibliotecas universitárias brasileiras. A intenção é apresentar algumas possibilidades de atuação, incentivando a discussão sobre o tema e a oferta de serviços de bibliometria e de apoio à comunicação científica em bibliotecas universitárias.

Os serviços de bibliometria e apoio à comunicação científica podem ser reunidos em três eixos principais:

a) Apoio institucional: constituem serviços de apoio institucional aqueles que fornecem subsídios para a melhoria da gestão, desenvolvimento, avaliação e divulgação da instituição:

- Disponibilização de repositórios e bases de dados da produção científica e tecnológica institucional,

- elaboração de relatórios de avaliação da produção científica e tecnológica institucional,

- Acompanhamento dos resultados dos rankings universitários,

- acompanhamento e divulgação de editais de fomento à pesquisa,

- $\quad$ apoio na preparação de dados de avaliação das atividades de pesquisa e pós-graduação para órgãos avaliadores e agências de fomento,

- levantamentos e análises bibliométricas por demanda institucional;

b) Apoio ao pesquisador: os serviços de apoio ao pesquisador e grupos de pesquisa referemse à assessoria nas atividades de comunicação científica, desenvolvimento de carreira e identificação de indicadores:

- Apoio na identificação de fontes de informação, revisão da literatura e revisão sistemática; 
- orientações sobre redação científica e estilos de normalização;

- apoio no uso de recursos de detecção de plágio;

- orientações sobre direitos autorais, licenças de publicação e direitos de uso da informação;

- orientações sobre depósito de produção científica em repositórios institucionais, incluindo o autoarquivamento;

- apoio no entendimento das políticas editoriais dos periódicos e das políticas de AA;

- $\quad$ orientações sobre atribuição e utilização do Digital Object Identification (DOI);

- apoio na identificação de revistas adequadas para publicar;

- orientações no uso de plataformas de submissão de artigos, a exemplo do Sistema Eletrônico de Editoração de Revistas (SEER), Scholar One e outras;

- orientações sobre depósito de dados científicos em repositórios institucionais ou temáticos, especialmente quando solicitados pelo periódico para publicação do artigo;

- levantamento de métricas individuais, a exemplo do Índice h, Google My Citations e outros indicadores tradicionais ou alternativos;

- apoio no correto preenchimento do Currículo Lattes;

- apoio na criação e atualização dos identificadores individuais de autores, como ORCID, ResearcherID e Scopus ID;

- apoio no gerenciamento das redes sociais acadêmicas: Academia.edu, Mendeley, ResearchGate e outras;

- apoio no registro da avaliação por pares em ferramentas de reconhecimento da atividade, como Publons e outros;

- orientações sobre a preparação de projetos e documentação para editais;

c) Formação e desenvolvimento de competências: ações voltadas à formação e ao desenvolvimento de competências informacionais de estudantes e pesquisadores, com diversos enfoques: 
- Identificação de fontes de informação, formas de busca e recuperação da informação, uso ético da informação etc.;

- gerenciadores de referências, como EndNote, Mendeley, Zotero e outros;

- redação científica e normalização de trabalhos acadêmico-científicos;

- indicadores tradicionais de produção, colaboração e impacto, altmetrias, indicadores individuais, Fator de Impacto, Qualis, entre outros;

- currículo vitae, incluindo Currículo Lattes e padrões internacionais;

- identificadores de autores: ORCID, ResearcherID e Scopus ID;

- redes sociais acadêmicas.

As ações de formação de competências informacionais parecem ser mais frequentes em bibliotecas universitárias brasileiras que os demais serviços elencados. Reforça-se aqui, a importância de que essas ações contemplem também a formação de pesquisadores para o aprimoramento da comunicação científica, para a gestão da carreira e o melhor conhecimento dos sistemas de avaliação. A oferta de serviços em bibliotecas universitárias precisa naturalmente acompanhar o ecossistema dinâmico de informação que se coloca na atualidade. Esse cenário gera um importante desafio às bibliotecas universitárias frente às métricas da comunicação científica, além de outros desafios igualmente relevantes em relação à produção e ao uso da informação no contexto dos programas de ensino, pesquisa e extensão das universidades. 


\section{Considerações finais}

A bibliometria é um instrumento auxiliar no plano estratégico e pode apoiar as universidades no conhecimento de seus pontos fortes e suas fragilidades. Os indicadores bibliométricos não só contribuem para aprovar projetos em editais, mas constituem subsídios importantes para a gestão, o planejamento e a avaliação das universidades, permitindo o acompanhamento e a verificação do cumprimento de objetivos institucionais.

Várias das atividades mencionadas neste trabalho já são correntes nas universidades brasileiras, realizadas tanto por órgãos da administração central das universidades, como por setores de assessoria de imprensa e bibliotecas. Defende-se a criação de estruturas para o oferecimento de serviços bibliométricos e de apoio à comunicação científica nas bibliotecas universitárias e a centralização das atividades de controle e divulgação dos resultados da pesquisa institucional por essas unidades. O bibliotecário é o profissional que detém conhecimento técnico e gerencial sobre fontes de informação, descrição, metadados, preservação digital e disseminação da informação. As atividades relacionadas à bibliometria compõem um nicho de trabalho e representam uma grande oportunidade no horizonte profissional.

A integração entre os serviços de apoio institucional, apoio ao pesquisador e formação e desenvolvimento de competências propostos neste trabalho tende a gerar efeitos positivos em toda a cadeia, com bons resultados nos níveis individual, institucional e de grupos de pesquisa, além de reflexos na avaliação da pesquisa nacional. A responsabilidade pela promoção desses serviços não se restringe, portanto, às bibliotecas universitárias enquanto órgãos competentes no assunto. Exige também, fundamentalmente, o compromisso e apoio integral das instituições, além do incentivo das agências de fomento e dos organismos nacionais de C\&T. 


\section{Referências}

ASSOCIATION OF COLLEGE \& RESEARCH LIBRARIES (ACRL). Framework for information literacy for higher education. Chicago, 2015. Disponível em: <http://www.ala.org/acrl/standards/ilframework>. Acesso em: 12 ago. 2017.

ASTROM, Fredrik.; HANSSON, Joacim. How implementation of bibliometric practice affects the role of academic libraries. Journal of Librarianship and Information Science, London, v. 45, n. 4, p. 316-322, set. 2012.

AYRIS, Paul. University and research libraries in Europe working towards Open Access. LIBER Quarterly, Munich, v. 20, n. 3/4, p. 332-346, fev. 2011.

BALL, Rafael; TUNGER, Dirk. Bibliometric analysis: a new business area for information professionals in libraries? Scientometrics, Amsterdam, v. 66, n. 3, p. 561-577, 2006.

BLANCO, Elena; CASALDÀLIGA, Anna. El papel de la biblioteca en la difusión de la producción científica en la Universitat Pompeu Fabra. El profesional de la Información, Madrid, v. 21, n. 6, p. 627-631, 2012.

COSTA, Janise Silva Borges da. et. al. Sistema de automação de bibliotecas da UFRGS: fonte de indicadores para avaliação. In: SEMINÁRIO NACIONAL DE BIBLIOTECAS UNIVERSITÁRIAS, 16., 2010, Rio de Janeiro. Anais... Rio de Janeiro: UFRJ, 2010.

CREASER, Claire; SPEZI, Valérie. Improving perceptions of value to teaching and research staff: the next challenge for academic libraries. Journal of Librarianship and Information Science, London, v. 46, n. 3, p. 191-206, 2014.

MyRI: measuring your research impact: supporting research through online bibliometrics training. 2015. Disponível em: 〈http://myri.conul.ie>. Acesso em: 09 ago. 2017.

DE-FILIPPO, Daniela et al. El papel de las bases de datos institucionales en el análisis de la actividad científica de las universidades. Revista Española de Documentación Científica, Madrid, v. 34, n. 2, p. 165- 189, 2011.

LEITE, Fernando César Lima. Como gerenciar e ampliar a visibilidade da informação científica brasileira: repositórios institucionais de acesso aberto. Brasília: IBICT, 2009.

MACCOLL, John. Research assessment and the role of the library. Dublin: OCLC, 2010. Disponível em: 〈http://www.oclc.org/research/publications/library/2010/2010-01.pdf >.

Acesso em: 15 ago. 2017.

MENA-CHALCO, Jesus Pascual; CESAR JUNIOR, Roberto Marcondes. ScriptLattes: an open-source knowledge extraction system from the Lattes platform. Journal of the Brazilian Computer Society, Porto Alegre, v. 15, n. 4, p. 31-39, dez. 2009.

IRIBARREN-MAESTRO, Isabel et al. Apoyando la investigación: nuevos roles en el servicio de bibliotecas de la Universidad de Navarra. El Profesional de la Información, Madrid, v. 24, n. 2, p. 131-137, 2015.

PÉREZ, Mónica Beatriz. Sobre las bibliotecas y los bibliotecarios especializados en ciencia y 
tecnología. Revista QuímicaViva, Buenos Aires, v. 9, n. 3, p. 156-166, 2010.

SILVA, Marcia Regina da; HAYASHI, Carlos Roberto Massao; HAYASHI, Maria Cristina Piumbato Innocentini. Análise bibliométrica e cientométrica: desafios para especialistas que atuam no campo. InCID: Revista de Ciência da Informação e Documentação, Ribeirão Preto, v. 2, n. 1, p. 110-129, 15 jun. 2011. Disponível em: <http://www.revistas.usp.br/incid/article/view/42337>. Acesso em:

TORRES-SALINAS, Daniel; JIMÉNEZ-CONTRERAS, Evaristo. Hacia las unidades de bibliometría en las universidades: modelo y funciones. Revista Española de Documentación Científica, Madrid, v. 35, n. 3, p. 469-480, 2012.

TORRES-SALINAS, Daniel; CABEZAS-CLAVIJO, Álvaro. Herramientas para la evaluación de la ciência en universidades y centros I+D: descripción y usos. Anuario ThinkEPI, Barcelona, v. 6, p. 142-146, 2012.

VARGAS, Rosely de Andrade. A produção científica brasileira em ciências agrárias indexada na Web of Science: características e redes de colaboração (2000-2011). Dissertação (Mestrado em Comunicação e Informação) - Universidade Federal do Rio Grande do Sul, Porto Alegre, 2014. Disponível em: <http://www.lume.ufrgs.br/handle/10183/102304>. Acesso em: 28 jul. 2017. 